\title{
INCURSÕES SOBRE OS TERMOS E CONCEITOS DA EDUCAÇÃO MUSEAL
}

\author{
INCURSIONS ON THE TERMS AND CONCEPTS OF MUSEUM EDUCATION
}

INDAGA EN LOS TÉRMINOS Y CONCEPTOS DE LA EDUCACIÓN MUSEÍSTICA

\author{
Sibele Cazelli \\ Maria Esther Valente
}

\section{RESUMO}

A educação em museu pode ser definida como um conjunto de valores, conceitos, saberes e práticas cujo objetivo é o desenvolvimento do visitante. Para abordar o tema, a proposta deste artigo é fazer algumas incursões sobre o entendimento de termos e conceitos da área em questão. Não se pretende fazer uma análise exaustiva, mas revisitar referências que destacam controvérsias de linguagem nas suas definições em diferentes países. Este interesse é motivado por indagações, ainda recorrentes, associadas à compreensão de termos como educação formal, não formal, informal e museal, que podem ser tornar confusos em função de suas finalidades. Isto porque são compartilhados por diferentes instituições com as quais se interrelacionam. Este fato ocorre, essencialmente, uma vez que a maior parte da literatura de caráter museológico difundida sobre os estudos de público provém de países ocidentais desenvolvidos e está e divulgada principalmente em inglês ou francês. Cotejando a literatura nacional e estrangeira pode-se estabelecer o caminho percorrido para a construção dos termos e conceitos usados na consolidação do corpo teórico da educação em museu. Considerando as definições do sociólogo francês Bourdieu, é possível entender a educação museal como um campo de conhecimento, ainda em construção, com pouca autonomia e em processo de acúmulo de capital científico. Neste sentido, busca-se contribuir para o adensamento deste tipo de educação, valorizando-a e legitimando-a, tanto no que diz respeito às suas práticas quanto aos profissionais que as desenvolvem.

PALAVRAS-CHAVE: Educação em Museus. Termos e Conceitos. Política.

\section{ABSTRACT}

Museum education can be defined as a set of values, concepts, knowledge and practices whose goal is the development of the visitor. This article proposes some incursions on the understanding of terms and concepts of this area. It is not intended to make an exhaustive analysis, but to revisit references that highlight language controversies in their definitions in different countries. This is motivated by still recurrent inquiries associated with the understanding of terms such as formal, non-formal, informal and museum education, which may be confusing in terms of their purposes. This is because these terms are shared by different institutions and it occurs mainly because most of the museological literature about public studies comes from developed western countries and is written mainly in English or French. Contrasting national and foreign literature can establish the path taken to construct the terms and concepts used in the consolidation of the theoretical body of museum education. Considering the definitions of the French sociologist Bourdieu, it is possible to understand museum

Submetido em: 12/03/2019 - Aceito em: 15/06/2019 - Publicado em: 31/08/2019. 


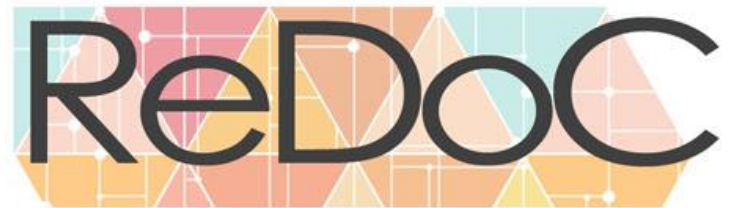

\section{Revista Docência e Cibercultura}

education as a field of knowledge, still under construction, with little autonomy and in the process of accumulation of scientific capital. In this sense, we seek to contribute to the consolidation of this type of education, valuing it and legitimizing it, both in terms of its practices and the professionals who develop them.

KEYWORDS: Museum Education. Terms and Concepts. Policy.

\section{RESUMEN}

La educación en museos puede definirse como un conjunto de valores, conceptos, conocimientos y prácticas dirigidos al desarrollo del visitante. Para abordar el tema, el propósito de este artículo es hacer algunos avances en la comprensión de los términos y conceptos del área en cuestión. No tiene la intención de hacer un análisis exhaustivo, sino de revisar las referencias que resaltan las controversias lingüísticas en sus definiciones en diferentes países. Este interés está motivado por preguntas, aún recurrentes, asociadas con la comprensión de términos como educación formal, no formal, informal y museal, que pueden ser confusos debido a sus propósitos. Esto se debe a que son compartidos por diferentes instituciones con las que se interrelacionan. Esto se debe esencialmente a que la mayor parte de la literatura museológica generalizada sobre estudios públicos proviene de países occidentales desarrollados y se publica principalmente en inglés o francés. Al comparar la literatura nacional y extranjera, es posible establecer el camino tomado para construir los términos y conceptos utilizados en la consolidación del cuerpo teórico de la educación museística. Considerando las definiciones del sociólogo francés Bourdieu, es posible entender la educación museal como un campo de conocimiento, aún en construcción, con poca autonomía y en el proceso de acumulación de capital científico. En este sentido, buscamos contribuir a la consolidación de este tipo de educación, valorándola y legitimándola, tanto en lo que respecta a sus prácticas como a los profesionales que las desarrollan.

PALABRAS CLAVE: Educación en museos. Términos y conceptos. Política.

\section{INTRODUÇÃO}

Em vários momentos, a criação de museus ou até mesmo sua remodelação se dá inserida no contexto de políticas públicas, promovidas pelo Estado e relacionadas a interesses de formação e instrução dos indivíduos e das coletividades. Embora não se possam descartar boas iniciativas voltadas para a educação em museus, desde o século XIX, foi somente a partir da segunda metade do século XX que seu papel educativo passou a ser formalmente reconhecido, tendo em vista a definição de seus contornos educacionais mais precisos dados às ações promovidas nestas instituições.

A partir da década de 1970 há uma grande ênfase no plano educativo, impulsionando uma mudança na perspectiva educacional dos museus, reflexo dos movimentos sociais da época em diferentes partes do mundo. A postura é assumida especialmente pelos museus de temática científica por meio da utilização de métodos interativos e populares, como forma de 


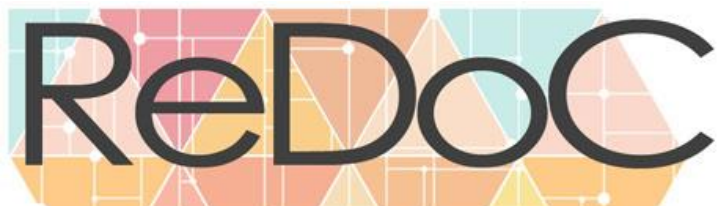

\section{Revista Docência e Cibercultura}

apreensão da cultura científica, voltados à promoção da participação mais direta de um público diversificado.

A despeito dos inúmeros entendimentos do termo cultura científica, existe algo comum a todos eles: a ideia de apropriação pelos indivíduos. Independentemente daquilo que se considere, seja o desenvolvimento da ciência, a democratização dos debates em torno dela ou a luta contra a alienação em uma sociedade cada vez mais norteada pelo desenvolvimento científico, esta ideia está presente. Godin e Gingras (2000, p. 44) interpretam a cultura científica como a "expressão de todos os modos por meio dos quais indivíduos e sociedade se apropriam da ciência e da tecnologia". Sobre esta noção, importa destacar que contempla tanto a dimensão individual como a social da ciência.

Das mudanças mais notáveis ocorridas na história recente dos museus, encontra-se exatamente o crescimento de seu papel associado à educação, refletido, inclusive, na contratação de profissionais específicos para os setores educativos. Estes vêm reivindicando uma participação cada vez maior e efetiva na concepção das exposições museológicas, no sentido de melhorar a comunicação com seus diferentes públicos. Existe, para isso, por parte de seus profissionais um empenho em tornar esta área fortalecida por meio do um conhecimento cada vez mais sólido e coerente que alia a teoria e a prática em suas ações.

Nesse sentido, a proposta deste artigo é fazer incursões sobre o entendimento de termos e conceitos da área de educação em museus. Não se pretende fazer uma análise exaustiva, mas revisitar referências que destacam controvérsias de linguagem nas suas definições em diferentes países. Este interesse é motivado por indagações, ainda recorrentes, associadas à compreensão de termos como educação formal, não formal, informal e museal, que podem ser tornar confusos em função de suas finalidades. Isto porque são compartilhados por diferentes instituições com as quais se interrelacionam. Este fato ocorre, essencialmente, uma vez que a maior parte da literatura de caráter museológico difundida sobre os estudos de público provém de países ocidentais desenvolvidos e está escrita principalmente em inglês ou francês. Cotejando a literatura nacional e estrangeira pode-se estabelecer o caminho percorrido para a construção dos termos e conceitos usados na consolidação do corpo teórico da educação em museus.

\section{EDUCAÇÃO: TERMOS E CONCEITOS}

Os fins da década de 1960 e início da de 1970, no quadro mundial, foram estimulantes e férteis para a abertura de novos espaços de educação. Começava a tomar corpo outro setor da educação que se deslocava da formalidade da escola, reconhecidamente em crise. Esse movimento tomou a denominação de educação não formal. A versão original do que seria este novo tipo de educação surgiu em uma publicação de Coombs (1968). 


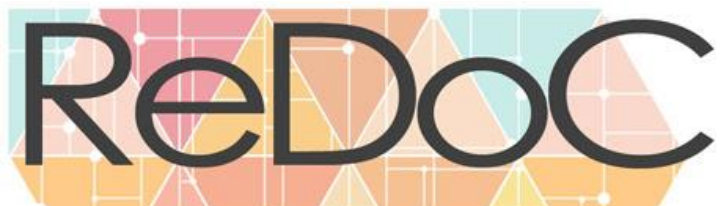

\section{Revista Docência e Cibercultura}

Nas duas décadas seguintes, a preocupação em definir essa nova área da educação gera uma importante produção tanto em número quanto em qualidade. Na educação em ciências, a revista americana Science Education abre um espaço para essa discussão, além de contar com uma seção sobre esse tipo de educação, recebendo artigos de várias partes do mundo. Trouxe em seu editorial comentários relacionados à aprendizagem de ciências que acontece em uma variedade de locais fora da escola e que continua após o término da educação formal das pessoas (DIERKING; MARTIN, 1997).

No que concerne à temática da educação que ocorre fora do contexto escolar, cotejando as literaturas anglofônica e lusofônica, percebe-se uma aparente controvérsia de linguagem para denominar este tipo de educação. Os autores de língua inglesa usam os termos, informal education (educação informal) e informal learning (aprendizagem informal) para designar todo o tipo de educação que usualmente acontece em lugares como museus, zoológicos, jardins botânicos, no trabalho, em casa, etc. Já os de língua portuguesa subdividem a educação realizada fora da escola em dois subgrupos: educação não formal e educação informal, sendo o último relativo aos meios de comunicação, na família, no trabalho, na rua, nos pontos de encontro, nos clubes, nos sindicatos, nos movimentos sociais. As próprias cidades vão se transformando em agências educativas.

No que diz respeito aos autores de língua inglesa, Dierking e Falk (1999) definem educação informal, por suas características: livre escolha, não sequencial, autoconduzida, voluntária e social. Wellington (1990) acrescenta outras características, como não estruturada, não avaliada, sem cobrança, aberta, centrada no aprendiz, não baseada em currículo. Crane et al. (1994) desenvolveram uma abordagem híbrida, na qual esta forma de educação sob certas condições pode acontecer dentro da escola. As atividades podem também servir como suplemento para a aprendizagem formal, mas as características que as distinguem é que elas foram desenvolvidas para a aprendizagem fora da escola.

Falk et al., (1986) e McManus (1992) chamam atenção para o fato de que não se deve assumir que a educação informal é menos importante do que a educação formal, porque se desvia da norma. Além disto, a comunidade educacional não deve ter expectativas de avaliá-la com o mesmo grau de precisão e confiabilidade que avalia a aprendizagem formal. A metodologia deve ser flexível e adaptável a este tipo de atividade/ambiente menos estruturado. Não podem ser as mesmas ferramentas e os mesmos testes aplicados na escola.

Analisando os autores de língua portuguesa, Fávero argumenta que a educação não formal é

[...] qualquer tentativa educacional organizada e sistemática que se realiza fora dos quadros do sistema formal (de ensino) para fornecer determinados tipos selecionados de aprendizagem a subgrupos específicos da população, tanto de adultos como de crianças. Assim definida, a educação não formal inclui, por exemplo, programas de extensão rural e treinamento de agricultores, programas de alfabetização de adultos, treinamento profissional dado fora do sistema formal, clube de jovens com objetivos em grande parte educacionais, diversos programas comunitários, de educação sobre saúde, nutrição, planejamento familiar, cooperativismo, etc. (FÁVERO, 1980, p. 22). 


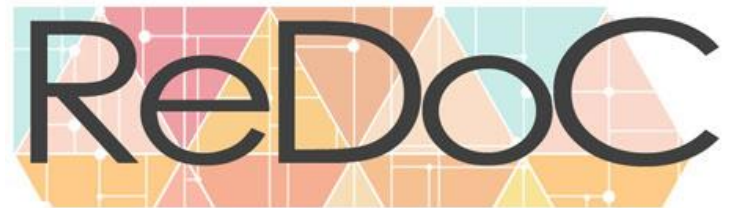

\section{Revista Docência e Cibercultura}

Já por educação informal, esse autor entende que é um

processo permanente pelo qual qualquer pessoa adquire e acumula conhecimentos, habilidades, atitudes e perspicácia, através de experiência diária e contato com o meio ambiente em casa, no trabalho e no lazer, através do exemplo e das atitudes dos parentes e amigos; por meio de viagens, leitura de jornais e livros; ou ouvindo rádio, vendo filmes e televisão (Ibid., p. 23).

Chagas sublinha que a educação não formal é "veiculada pelos museus, meios de comunicação e outras instituições que organizam eventos de diversas ordens, tais como cursos livres, feiras e encontros, com o propósito de ensinar a um público heterogêneo". Deste modo, a "aprendizagem não formal desenvolve-se de acordo com os desejos do indivíduo, em um clima especialmente concebido para se tornar agradável". Sobre a educação informal diz que "ocorre de forma espontânea na vida do dia-a-dia por meio de conversas e vivências com familiares, amigos, colegas e interlocutores ocasionais" (CHAGAS, 1993, p. 52).

Gohn chama a atenção para o fato de que atualmente,

não importa mais possuir um grande acervo de conhecimentos, mas sim o domínio de certas habilidades básicas, tais como comunicar-se (de preferência em mais de uma língua), domínio da linguagem das máquinas e, sobretudo, habilidades de gestão (de gerir sua própria carreira, equipes, conflitos, etc.). Todos têm de planejar e administrar suas vidas e carreiras (GOHN, 1999, p. 95).

Por isso, essa autora considera que a expressão educação não formal designa um processo com dimensões. A primeira envolve a aprendizagem política dos direitos dos indivíduos enquanto cidadãos. A segunda diz respeito à capacitação dos indivíduos para o trabalho, por meio de aprendizagem de habilidades. A terceira abrange a aprendizagem e o exercício de práticas que habilitam os indivíduos a se organizarem com objetivos voltados para a solução de problemas coletivos. A quarta abarca a aprendizagem dos conteúdos da escolarização formal, em formas e locais diferenciados. Ressalta ainda uma quinta dimensão, isto é, a educação desenvolvida na e pela mídia, em especial a eletrônica. Ao tratar dos espaços onde se desenvolvem as atividades de educação não formal, destaca as associações de bairro, as igrejas, os sindicatos, os partidos políticos, as organizações não governamentais, os espaços culturais e as próprias escolas, ou seja, nos espaços interativos destas com a comunidade educativa. Também não enquadra a educação transmitida pelos pais na família, no convívio com amigos, clubes, teatros, leitura de jornais, livros, revistas, na área da educação não formal. Diz que são questões da educação informal, uma vez que esse tipo de educação tem um caráter espontâneo e permanente, isto é, ocorre nos espaços de possibilidades educativas no transcorrer da vida dos indivíduos. 
Cotejando os três autores de língua portuguesa acima citados, percebe-se que no entendimento de Fávero (1980), as iniciativas de caráter educacional e cultural desenvolvidas em museus, zoológicos, jardins botânicos não estão contempladas no subgrupo da educação não formal. No entanto, na concepção de Chagas (1993), o que se nota é o oposto. Mesmo Gohn (1999), ao traçar as dimensões da educação não formal e ao relacionar os locais onde ela ocorre, não explicita o que são os espaços culturais mencionados. Portanto, não fica claro se museus e outros locais correlatos estão aí incluídos. É possível estabelecer, na abordagem desta última autora, aproximações com o potencial educacional dos museus. No que diz respeito à dimensão que trata da aprendizagem que habilita indivíduos a se organizarem com objetivos de solucionar questões coletivas, pode-se dizer que ela vem ao encontro de alguns dos atuais aspectos da função educativa destas instituições. Por exemplo, o de apresentar e testar ideias alternativas de temáticas controversas em suas exposições; o de oferecer diferentes perspectivas culturais, intelectuais, dar voz a muitas experiências e pontos de vista; o de possibilitar o encontro de grupos onde as experiências enriquecedoras se dão por meio da interação humana e das ideias.

Quanto à dimensão que considera a aprendizagem dos conteúdos da educação formal, em formas e espaços diferenciados, observa-se novamente a existência de pontos de contato. Os museus procuram compartilhar com outras instituições educativas a responsabilidade de ampliar as oportunidades de aprendizagem, além de informar, nutrir e ilustrar os indivíduos acerca do valor do conhecimento sobre seu passado e presente, com vistas ao futuro. Isto faz com que os objetivos da educação não formal possam estar direcionados para a socialização de conhecimentos historicamente produzidos e organizados pelos indivíduos de forma diferenciada daquela realizada na escola (os recursos museais são facilitadores para a apresentação dos conhecimentos historicamente produzidos).

A educação não formal tem também características coletivas, uma vez que muitas das experiências são vivenciadas em grupo. As relações sociais aí implícitas são marcadas por um caráter de intersubjetividade, ou seja, que se passa entre agentes.

Reunindo essas características acima apresentadas, falta assinalar uma que é o destaque da educação não formal e que a diferencia, por exemplo, da informal. Esta característica é a intencionalidade da instituição, bem como a dos idealizadores das ações (no caso dos museus, os conceptores das exposições e das atividades de cunho educacional e cultural), com objetivos de unir cultura, saberes e lazer.

Com o intuito de delimitar fronteiras entre a educação formal e a não formal, pode-se dizer que ambas compartilham, além da existência de intencionalidade - objetivos explícitos de 


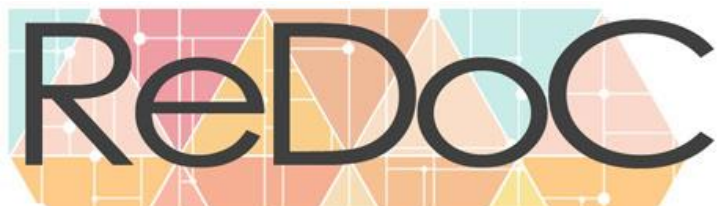

\section{Revista Docência e Cibercultura}

aprendizagem - o fato de se constituírem como processos educativos diferenciados e específicos. Possuem também estrutura e organização, mas são estritamente distintas. Trilla (1998) apresenta dois critérios por meio dos quais se podem estabelecer as fronteiras entre estes dois tipos de educação. Um deles, o "metodológico", define o formal como o escolar e o não escolar como o não formal.

A partir desse critério há o estabelecimento de uma dicotomia na caracterização dos dois tipos de educação. No entanto, outras formas vêm sendo elaboradas no sentido de distinguir a educação não formal e sua relação com as demais esferas do universo educacional. Autores como Hofstein e Rosenfeld (1996) e Rogers (2004) entendem que ambas devem ser vistas como um continuum, já que suas distintas características se interpenetram.

O outro critério apresentado por Trilla (1998) para estabelecer diferenças entre educação formal e não formal é o "estrutural", segundo o qual elas se particularizam não por seu caráter escolar ou não escolar, mas por sua inclusão (formal) ou não inclusão (não formal) na esfera da educação graduada e hierarquizada, que se orienta pela obtenção de títulos acadêmicos. Percebe-se aqui que o espaço físico é insuficiente para definir o caráter das práticas educativas que nele se encerram, visto que as práticas educativas não formais podem ter lugar no espaço físico da escola, assim como práticas formais podem ocorrer (e de fato ocorrem) em lugares como os museus, tidos como espaços de práticas não formais.

Trata-se de um conjunto de processos, meios e instituições específicas e diferentemente organizadas, que possuem objetivos explícitos de formação ou de instrução; não se caracterizando, por sua vez, pela hierarquização e sequencialidades próprias do sistema educativo regrado. Outros aspectos que devem ser apontados se referem ao fato de que nos espaços de educação não formal os indivíduos não têm a "obrigação" de aprender e seus conhecimentos não são colocados à prova. Além disso, essas instituições não possuem a função social de certificação do aprendizado (Ibid.).

Se por um lado, de alguma maneira o conhecimento produzido sobre o papel educativo dos museus procurou se apoiar na base consolidada da educação como seu referencial, hoje, sem abandonar o saber adquirido ao longo de décadas, refletir sobre a dimensão educativa deste antigo espaço é se aproximar das fontes mais ligadas às ciências sociais que norteiam a museologia. A ocupação central do museu no universo cultural da sociedade exige dele uma nova missão de natureza bastante complexa. Neste processo, a educação em museus toma outra identidade, incorporando um novo termo, a educação museal. Desta forma, os modelos educativos devem ser readaptados ou mesmo reinventados, o que representa para seus profissionais um grande desafio. 
Foram destacados alguns termos que predominam no vocabulário da educação em museus, o que não significa que muitos outros poderiam ser incluídos. Sem analisá-los, vale atentar para o uso de outras expressões adaptadas para a educação em museus que vão denotar aspectos particulares: pedagogia de museu, mediação, educação integral, entre outros.

Allard e Boucher, pesquisadores canadenses, citados no Dictionnaire Encyclopédique de Muséologie (DESVALLÉES; MAIRESSE, 2011, p. 87) destacam que

[...] a pedagogia de museu é um quadro teórico metodológico que está a serviço da elaboração, implementação e avaliação de atividades educativas em um ambiente de museu, atividades estas que têm como objetivo principal a aprendizagem dos saberes (conhecimentos, habilidades e atitudes) pelo visitante.

No que concerne à aprendizagem, esses autores a definem como "um ato de percepção, interação e integração de um objeto por um sujeito", o que conduz a uma "aquisição de conhecimentos ou ao desenvolvimento de habilidades ou de atitudes" (Ibid.).

Ainda, no Canadá, que é um país bilíngue, usa-se o termo l'éducation muséale, no francês, e education in museuns, no inglês, embora estes termos não estejam atrelados a uma definição particular.

$\mathrm{Na}$ Alemanha, fala-se mais em pädagogik (pedagogia) e quando se fala de pedagogia no contexto do museu, se diz museumspädagogik (pedagogia de museu). Neste caso, a pedagogia se refere às atividades oferecidas para os diferentes públicos, independentemente da idade, formação e origem social (Ibid., p. 88).

Tomando as reflexões de McManus (2009, p. 49), a autora sublinha a necessidade de "ponderar sobre o que queremos significar ao dizer, ou pensar, palavras como educação, aprendizagem e interação". Argumenta que se tende a usar estes conceitos/termos sem reflexão, o que leva a uma compreensão intuitiva, comprometendo a consistência das ações educativas realizadas nos museus.

De todo modo, delimitar fronteiras é importante, não para definir até onde podemos ir, mas para demarcar a passagem de um lado ao outro, para diferentes objetivos, intencionalidades, estratégias. No entanto, usando a figura das coordenadas geográficas, as fronteiras entre educação formal, não formal, informal e agora museal não são paralelos ou meridianos, latitude ou longitude, imóveis ou fixos, mas sim linhas, contornos que podem constantemente ser refeitos, ora avançando, ora recuando. Demarcá-las é respeitar suas diferenças, 


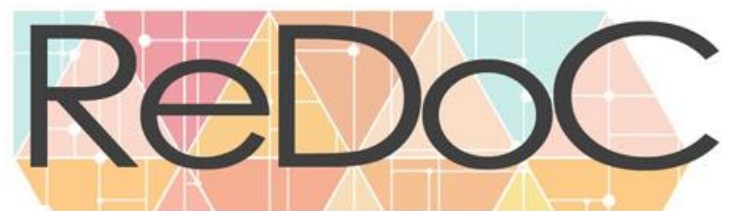

\section{Revista Docência e Cibercultura}

possibilitando assim profícuos encontros entre as diversas formas de educar (COSTA, 2009).

\section{EDUCAÇÃO EM MUSEUS: DIFERENTES CONCEPÇÕES}

Este item não tem a pretensão de retratar um quadro completo das concepções educacionais em museus. Serão abordadas, tão somente, algumas perspectivas que recuperam aspectos mais gerais da natureza das formas de apropriação da educação nestes espaços.

Ao longo do tempo, os museus têm evoluído para abarcar inúmeras funções e públicos diversos. Vão de coleções de objetos raros e históricos fechadas em instituições seculares, distantes da maior parte da sociedade, organizadas para fins de pesquisa e/ou deleite pessoal, até se manifestarem como museus públicos, que fazendo uso de linguagens mais palatáveis, buscam uma aproximação com diferentes visitantes, provenientes de todas as camadas da sociedade.

No fim do século XVIII e durante o seguinte, os países marcados pelas revoluções sociais, políticas e expansão colonial fomentam o nascimento dos museus públicos - aqueles que são usualmente identificados como de cunho nacional.

No Brasil, um exemplo emblemático foi o Museu Nacional - MN, criado em 1818. É oportuno reforçar a ideia de que o museu do "povo" deve ser entendido dentro das restrições de cada nação, nos limites do entendimento do sentido de igualdade dos indivíduos nos diferentes momentos históricos, embora não se menospreze o impacto que, a partir daí, provocou no museu a aceitação de camadas excluídas da população (VALENTE, 2018).

Na mesma ordem, os museus das Américas, instalados entre os séculos XIX e XX, vão aparecer com o mesmo entusiasmo de repetir as instituições europeias. A missão pedagógica destes museus foi a de imprimir junto à sociedade um ideal de nação, observado como veículo de moralidade. Educando, polindo e aperfeiçoando o olhar do "povo" por meio do discurso vigente, apresentado nas exposições. Evidenciando desta maneira que o saber está no museu, apresentado na forma que foi concebido para ser exposto e visto. Naquele momento, o tipo de visitante para o qual o museu estava apresentado priorizava a elite letrada.

Já no início do século XX, o exemplo marcante de incorporação da educação como papel fundamental dos museus tem como protagonista Edgard Roquette Pinto. Foi em sua gestão, a frente do MN, que em 1927 inaugurou a Seção de Assistência ao Ensino - SAE. Iniciativa da qual se destaca o empréstimo de espécimes às escolas, divulgando desta forma a história 


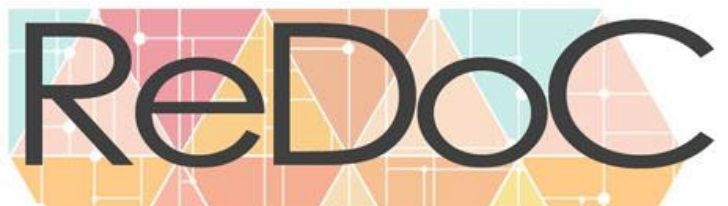

\section{Revista Docência e Cibercultura}

natural que era estudada no Museu. Uma década depois, Bertha Lutz procura conferir à mesma instituição um caráter mais atualizado. A pesquisadora, ao retornar em 1932 de um estágio nos museus americanos, inspirada em tudo que viu, também estimula no MN o valor da importância da função educativa. Em poucas palavras, identificava o modelo inovador de museu, aquele voltado a "intervir ativamente na formação cultural do público" em oposição ao museu estático que mantinha "intacto seu papel de ampliador dos conhecimentos humanos" (LOPES, 2008, p. 21).

Comparando esse momento que registra alterações marcantes na função educativa dos museus, com o longo período que se segue, poucas serão as mudanças significativas. Entretanto, cabe marcar que mesmo de forma discreta, nos museus públicos brasileiros, ideias veiculadas por Anísio Teixeira estimularam o aprofundamento do pensamento sobre a função educativa dos museus (VALENTE, 2018).

$\mathrm{Na}$ Europa, assim como no Brasil, a inspiração para as práticas educativas dos museus foi influenciada também por seus pares norte-americanos, que vinham disseminando os modelos de ateliês concebidos para crianças, onde os jovens poderiam exercitar suas experiências. Iniciativa que na França, a exemplo de outros países, sofreu críticas agudas por parte dos profissionais dedicados à pesquisa e à preservação, de quem sempre encontraram resistência. A queixa como descrita por Gesché-Koning (2006, p. 31) era a de que "o templo das musas europeias subitamente se viu repleto de crianças chegando para perturbar a tranquilidade do conservador imponente em sua torre de marfim".

Segundo Cassin (2006), especialista em museus de arte, a função educativa nos museus norteamericanos quando foram fundados era seu principal propósito. Para o autor, tratava-se de uma educação que apresentava a perspectiva particular de seus fundadores, ou seja, percebida como prática educativa, mais ativa que reflexiva.

Nesse movimento de ampliação do papel educativo dos museus, apesar das ideias educacionais que passaram a conferir maior liberdade ao visitante, a concepção escolarizante surge como dominante e foi fortalecida ao longo do século XX. No Brasil, uma crítica contundente a este modelo vem de Lopes (1991, p. 451), referência importante para repensar a relação do público com o museu, sublinhando que "a proposta educativa dos museus é diferente da proposta da escola", inclusive por se tratar essencialmente de uma linguagem visual e não verbal, sem ordem sequencial ou urgência de aprendizado, prazos e planejamentos. A autora, ao propor a desescolarização do museu, considera ainda que a questão educacional nestes espaços precisa lidar com a "separação que se dá no processo de produção e disseminação de conhecimento. [...] Separação entre as pesquisas de novos 


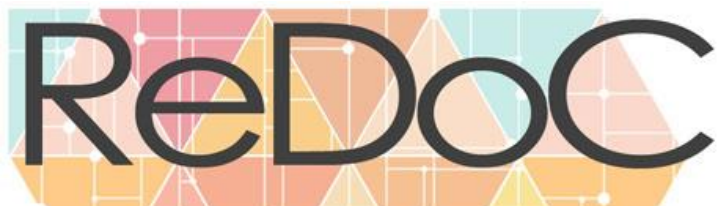

\section{Revista Docência e Cibercultura}

aspectos da realidade e sua veiculação realizada pelas exposições e atividades culturais e educativas" (Ibid, p. 453).

As mudanças no mundo dos museus foram sendo sentidas à medida que as concepções das exposições, abertas ao público, passam a ter caráter mais didático, diferente das apresentações exaustivas das coleções de estudo. Modelo que demarcou uma nítida separação entre as propostas educativas e a pesquisa, bem como entre os papéis do educador e do cientista. Cassin (2006) sublinha que mesmo os museus americanos, que propagavam ações educativas dinâmicas, passaram de coleções de ensino a instituições de pesquisa e destas, rapidamente, para o que também chamou de "torres de marfim".

De modo geral, nas décadas de 1960 e 1970, os museus, que pareciam congelados, sofreram acirradas críticas por manter ainda um perfil conservador, distante dos interesses da sociedade. É possível dizer que fatores como a escassez de recursos financeiros e de pessoal para atender as necessidades de funcionamento não eram os únicos ou até os principais entraves para as mudanças conceituais de educação nos museus. Entre eles, pode-se destacar o distanciamento entre profissionais de diferentes setores, enfatizado de forma recorrente, ainda hoje, por aqueles que trabalham na área educativa. Situação que tem raízes nas diferentes concepções que dão origem aos principais museus sejam eles da Europa ou das Américas.

Esses espaços museológicos, caracterizados por serem exclusivos para intelectuais especializados, deixavam aparente uma contradição. Eram em parte financiados por recursos públicos provenientes da maioria da população, que em geral era excluída. Pouco habituada a frequentar museus, não se identificava como pertencente a estes ambientes. Passa, então, a pressionar para que o retorno de seu investimento fosse recompensado e a pleitear mudanças profundas na concepção da acessibilidade pública dos museus, exigindo que fosse ali representada. Na França, por exemplo, os movimentos sociais de 1968 reivindicaram fortemente a reforma dos museus conservadores.

Inicialmente, em resposta a essa tensão e à necessidade de tornar as instituições museológicas socialmente mais acolhedoras, foram adotadas outras formas de conceber exposições interativas e atividades educativas que afirmassem os museus como espaços "divertidos", onde os displays apresentavam a resposta certa, reforçada por luzes que se acendiam ou sons que ecoavam. Estes eram enriquecidos por aparatos interativos que se difundiram pelo mundo com a famosa denominação hands-on. A ideia do "aprender fazendo" encontrou rapidamente nos museus interativos de ciência um meio de divulgação. Para Cassin (2006, p. 22), os responsáveis pelos museus impulsionaram intensamente esta mudança, provocando uma 


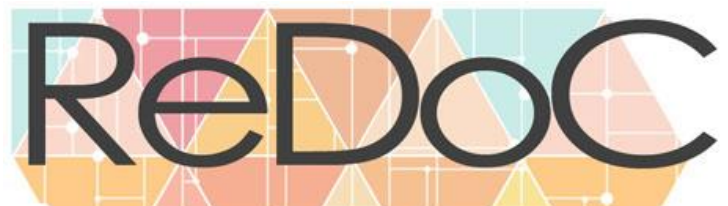

\section{Revista Docência e Cibercultura}

guinada, na qual os "museus foram de 'torres de marfim' para 'playgrounds' em uma só penada". A partir dos anos de 1980, foram muito disseminados pela reprodução de uma série de aparatos, caracterizando uma verdadeira indústria de museus interativos.

A principal crítica a esse modelo de museu era a ausência de conexão entre os visitantes e os saberes contidos nos aparatos. Em contraponto a esta contestação, teve início uma nova reviravolta na concepção da educação em museus que passa a ser definida como um conjunto de valores, conceitos, saberes e práticas que objetivavam o crescimento do visitante. Este crescimento deve ser entendido não só como ganho cognitivo, intelectual, mas acima de tudo como desenvolvimento psicológico que motiva para o aprendizado ao longo da vida. O tipo de educação aqui referido está ligado à mobilização do saber, ou seja, de como utilizar os recursos do museu para o crescimento dos indivíduos, estimulando sua capacidade de desenvolver novas sensibilidades e vivenciar novas experiências. Trata-se, portanto, de um processo que auxilia na construção da relação entre museu e sociedade, uma vez que tanto o museu quanto a educação são ferramentas importantes para uma efetiva democratização.

Apesar dos inúmeros entraves, as últimas décadas do século $\mathrm{XX}$ foram celeiro de uma formação acadêmica que subsidiou as reflexões e práticas da educação em museus nos mais diferentes países. No Brasil, esta circunstância coincide com o modelo de educar, associado com a filosofia da educação, em uma linha histórico-crítica que incorpora o construtivismo como corrente pedagógica. Além disso, procura absorver o entendimento da construção do conhecimento coletivo à luz da proposta emancipadora de Paulo Freire, embora, na maior parte das instituições não fique explícito em que linha teórica se baseia para atuar.

Nos museus, a educação mobiliza os diferentes saberes presentes, notadamente, nas narrativas expositivas e atividades educativas elaboradas pelos seus diversos profissionais. Estas ações são compreendidas, não como definitivas na aprendizagem que ocorre nos museus, mas sim como elementos mediadores na dinâmica dos processos cognitivos. São ambientes privilegiados na promoção de momentos socialmente partilhados de apropriação do conhecimento a partir de leituras, trocas de ideias e vivências de experiências. Dialogar ao mesmo tempo com múltiplas audiências, ampliar as representações sociais e culturais no seu espaço, é um movimento importante. Entender o aspecto excludente dos museus e compreender porque grande parte da população simplesmente não vê a visitação como podendo fazer parte do repertório de sua prática cultural, é um desafio (COIMBRA et al., 2014).

No entanto, ainda existe, na atualidade, uma falta de diálogo entre os museus e os numerosos grupos sociais na elaboração de propostas museográficas que os representem. Deste modo, a 


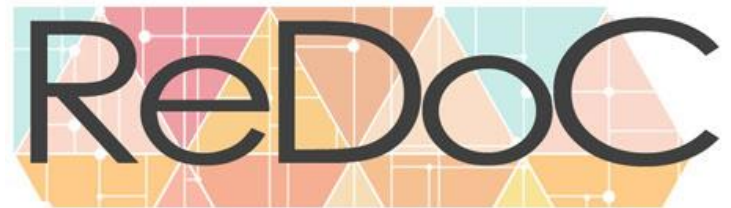

\section{Revista Docência e Cibercultura}

participação do grande público é uma questão que está para ser resolvida. Em muito casos existem grandes lacunas e um déficit real de cooperação nas propostas dos museus. "Ao contrário do que ocorre com os centros e associações culturais, os museus continuam sendo instituições produtoras de elites políticas, espaços de poder distanciados da maioria da sociedade e ausentes em muitos territórios" (AVILÉS et al. 2017, p. 64).

Os museus de hoje e de amanhã necessitam de todo tipo de ajuda. Carecem de reorganizar suas áreas de expertises voltadas para os especialistas e o público: pesquisa curatorial, investigação baseada nos objetos, conservação, design de exposição, estratégias de comunicação, planos de marketing criativo e programas educativos que provoquem a reflexão e a imaginação das diversas audiências. "É necessário formar uma geração de curadores que se interesse pelo público e uma geração de educadores de museus que se interessem pela pesquisa" (CASSIN, 2006, p. 23).

Considerando a questão levantada pelo autor acima citado, associada à necessidade de formar educadores de museus-pesquisadores, no Canadá essa preocupação vem desde o final da década de 1970. Atuação que culmina com a fundação em 1993 do Groupe d'intérêt espeécialisé sur l'éducation et les musées - GISEM. Fruto do empenho de pesquisadores provenientes de diferentes universidades canadenses (ALLARD et al., 2006).

No Brasil, a Coordenação de Educação em Ciências do Museu de Astronomia e Ciências Afins - MAST, unidade de pesquisa do Ministério da Ciência, Tecnologia, Inovações e Comunicações - MCTIC, consolidou a ideia de dar à Coordenação um perfil de pesquisa e não somente um setor que elabora e implementa programas ou atividades. Para tal, em 1991, sua equipe de pesquisadores cadastrou no Diretório dos Grupos de Pesquisa no Brasil/CNPq, o Grupo de Pesquisa em Educação Não Formal em Ciências - GECENF², com duas linhas de pesquisa: Divulgação da Ciência, Educação e Avaliação, e Cultura científica, Comunicação e Cognição. Este Grupo foi um dos primeiros a desenvolver estudos em educação na área. Há quase três décadas, o GECENF vem contribuindo de forma constante na publicação de artigos e livros e está associado a diferentes cursos de pós-graduação, tanto lato quanto strict sensu (CAZELLI et al., 2015).

Outra importante iniciativa brasileira é o Grupo de Estudo e Pesquisa em Educação Não Formal e Divulgação em Ciência - GEENF. Criado em 2002 é vinculado à Faculdade de Educação da USP, na área temática de Ensino de Ciências e Matemática. Dedica-se ao

\footnotetext{
${ }^{2}$ O GECENF,originalmente, foi nomeado como Grupo de Pesquisa em Educação em Ciências em Espaços Não Formais.
} 


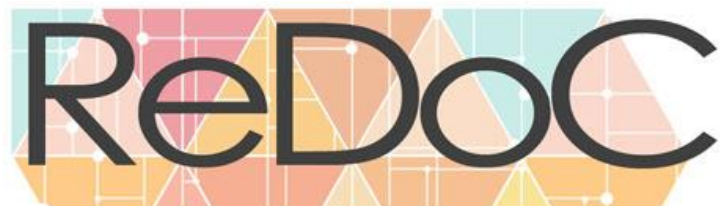

\section{Revista Docência e Cibercultura}

estudo, à pesquisa, à produção e avaliação de ações e materiais no campo da educação não formal e da divulgação em ciência. Este grupo atua em parceria com diversas instituições museológicas e de pesquisa, nacionais e internacionais, como museus, centros de ciências, zoológicos, jardins botânico, aquários, entre outros espaços de educação não formal (GEENF, 2019).

Observando outra questão levantada por Cassin (2006), no que se refere à necessidade de formar uma nova geração de curadores que se interesse pelo público, a publicação $L a$ formation en muséologie et en éducacion muséale à travers le monde (ALLARD; LEFEBVRE, 2001) se aproxima do tema. Ela traz inúmeras pesquisas que abordam a situação dessa área do conhecimento nas três últimas décadas do século XX. Dentre elas, vale considerar o resultado de uma investigação realizada na França. No que concerne à formação de profissionais da museologia, a educação em museus ocupa, na grade curricular, um lugar de pouca importância, o que se contrapõe à nova missão do museu, comprometida com as demandas sociais. Em relação a esta evidência, Cordier (2001) assegura que não pode haver profissão de museólogo que não leve em conta uma maior participação dos diferentes públicos de museus. Neste sentido, estes podem e devem ter papel mais ativo nas formas de envolvimento com o que os espaços museais propiciam.

Os diferentes discursos da educação crítico-social trazidos para os museus, além da incorporação de seus novos princípios, ocorre em função dos ambientes sociais, políticos e econômicos de cada país para a implantação de projetos. No entanto, apesar do esforço de promover mudanças, a defasagem entre o discurso e a prática permanece e encontra muitas vezes fortes resistências. As observações abordadas neste item substanciam muitos dos obstáculos para a valorização da dimensão educativa dos museus. E sinalizam que a dificuldade em obter reconhecimento se inscreve dentro e fora da instituição museológica, tornando o enfrentamento de suas questões mais complexo.

\section{A POLÍTICA DA EDUCAÇÃO EM MUSEUS}

Depois de um lento e longo declínio na primeira metade do século XX, os elementos chave da transformação dos museus aparecem nos anos de 1970 no cerne das organizações internacionais. A reflexão conduzida na comunidade de especialistas se concretiza por meio da criação de serviços especializados no âmbito das diversas administrações públicas e se traduz pela elaboração de políticas culturais nacionais. Dentro do quadro destas políticas, os numerosos programas e projetos são implementados. Um verdadeiro processo de desenvolvimento influi de maneira significativa sobre as condições nas quais se exerce a 


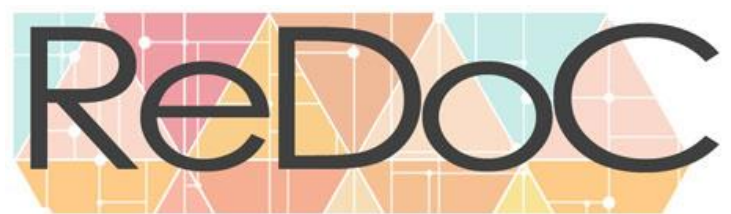

\section{Revista Docência e Cibercultura}

atividade dos museus.

Em busca da democracia e da modernidade, 1968 é um marco de ruptura no conjunto das sociedades ocidentais. Paradoxalmente, a crise era, na verdade, um sinal de renovação. De fato, nos anos 1970 nos Estados Unidos e 1980 e 1990 na Europa, os museus conhecem uma mudança radical que anunciam seu futuro de expansão.

Dentro desse clima de tensão internacional, diferentes países tentam se organizar para dar sentido à antiga instituição. Instâncias internacionais contribuíram amplamente para a reflexão sobre o futuro dos museus: Conselho Internacional de Museus (ICOM), Conselho Internacional de Sítios e Monumentos (ICOMOS), Organização das Nações Unidas para a Educação, a Ciência e a Cultura (UNESCO), entre outras. Profissionais especializados e modos de organização revalorizaram o acesso público ao patrimônio cultural. Para tal, são tomadas medidas por meio de ações de estado planejadas em programas, planos, projetos e políticas públicas (BALLÉ; POULOT, 2004).

Nos mais diferentes países teve início a elaboração de uma concepção moderna de museu, seja público ou privado, que passa a abarcar um novo quadro de funções e ofícios: administração, difusão, programação, financiamento, gestão de projetos, acolhimento de público, comercialização de produtos, etc. Ações que contribuíram para dar maior visibilidade à instituição.

Nesse cenário, na América Latina, a Mesa-Redonda de Santiago do Chile (1972) promoveu o debate para a renovação dos museus. É interessante observar o confronto entre as ideias vistas como renovadoras com aquelas cristalizadas e conservadoras do mundo museológico. Segundo Teruggi (1973) foram os especialistas de outras ciências que estimularam os museólogos a refletir sobre essa realidade que, para o bem ou para o mal, se impunha.

A direção que predominou na discussão foi a que exigia mudanças de mentalidade impulsionadas por um novo cenário político e econômico mundial. Repentinamente apresentou-se uma situação que exigia uma mudança de atitude por parte de todos no museu. E ficou claro que esse grande desafio, a exemplo da própria organização do Encontro, que contou com pesquisadores de diferentes domínios do conhecimento, não poderia ser assumido pelo museólogo sozinho ou por qualquer outro especialista. O museu, a partir de então, deveria recorrer a um conjunto de especialistas que incorporassem outros campos do saber. $\mathrm{O}$ trabalho da nova abordagem deveria ser feito em equipe para que se pudesse tirar o maior proveito das atividades voltadas para o público. 


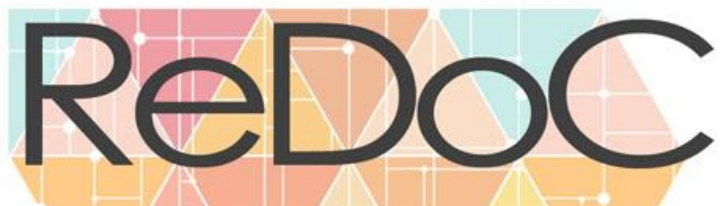

\title{
Revista Docência e Cibercultura
}

O contexto econômico-político e social da América Latina, em geral, era apresentado de forma bastante desfavorável. No caso brasileiro, acrescia-se a presença de um governo autoritário que cerceava o debate e dificultava a implementação de iniciativas que propusessem mudanças de cunho transformador. Apesar deste quadro, diferentes missões da UNESCO no Brasil visaram estudar as condições do Instituto do Patrimônio Histórico e Artístico Nacional (IPHAN) e dos museus, além de uma série de iniciativas governamentais que procurou a reorganização dos setores voltados para a preservação do patrimônio cultural brasileiro, como por exemplo, o Programa das Cidades Históricas, de 1973.

As décadas de 1970 e 1980 alicerçaram as bases para o lançamento em 2003 da Política Nacional de Museus (PNM), que desenvolveu "várias ferramentas de elaboração participativa de políticas públicas que deram origem, por exemplo, ao Plano Nacional Setorial (PNSM), como um desdobramento do Plano Nacional de Cultura no campo dos museus" (IBRAM, 2018, p. 18). Esta iniciativa contemplou a formação e capacitação de recursos humanos das instituições museológicas, principalmente, dos profissionais ligados à educação. Na sequência, outro marco de referência foi a criação do Estatuto de Museus no ano de 2009.

No âmbito dessas políticas e com o propósito de se estabelecer um fórum permanente de debate, foi criada a Rede de Educadores em Museus do Estado do Rio de Janeiro, em 2003.

Ao longo de sua trajetória

\begin{abstract}
se consolidou como um espaço fundamental aos educadores em museus não somente pela possibilidade de compartilhamento de ideias, mas, sobretudo, por estabelecer uma nova dinâmica nas relações entre os pares, viabilizada pelo trabalho em rede. Prova cabal do sucesso desta experiência tem sido a criação de redes em diferentes estados brasileiros que se utilizam do modelo da rede do Rio de Janeiro como inspiração (RANGEL, et. al., 2012, s/p.).
\end{abstract}

A forma de atuação das REMs, organizando seus encontros regionais e nacionais em parceria com outras instituições da sociedade, foi um processo democrático para a elaboração da Política Nacional de Educação Museal (PNEM), aprovada em 2017 e definida como

um conjunto de princípios e diretrizes com o objetivo de nortear a realização das práticas educacionais em instituições museológicas, fortalecer a dimensão educativa em todos os espaços do museu e subsidiar a atuação dos educadores (IBRAM, 2018, p. 128).

No artigo primeiro, a Política destaca que seu objetivo é fortalecer o campo da educação museal no Brasil, pois, apesar de a educação ser inerente aos museus, as práticas educacionais têm se configurado de modo disperso ou mesmo inexistente. Para assegurar que estas práticas sejam desenvolvidas de forma fundamentada, estável e contínua, seu Princípio 3 visa 


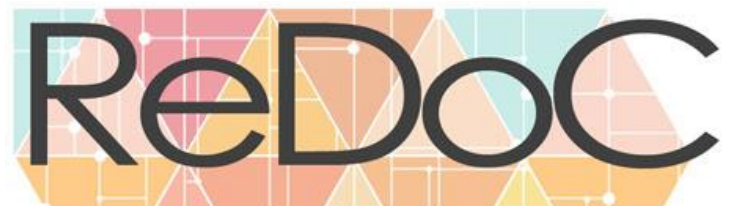

\section{Revista Docência e Cibercultura}

garantir que cada instituição possua setor de educação museal, composto por uma equipe qualificada e multidisciplinar, com a mesma equivalência apontada no organograma para os demais setores técnicos do museu, prevendo dotação orçamentária e participação nas esferas decisórias do museu (IBRAM, 2018, p. 45).

Para que o setor educativo dos museus tenha efetividade é importante considerar no âmbito das diretrizes dessa Política o Eixo II - Profissionais, Formação e Pesquisa, que é constituído de uma série de itens. O Item 1 ressalta um aspecto muito importante relacionado à Instituição: "promover o profissional de educação museal, incentivando o investimento na formação específica e continuada de profissionais que atuam no campo" (IBRAM, 2017, p. 6). Além disto, é crucial reconhecer que o desenvolvimento de pesquisas nesses setores subsidia a prática educativa, dando a ela consistência e credibilidade, o que é especificado nos Itens 7 e 8 do Eixo II: "fortalecer a pesquisa em educação em museus e em contextos nos quais ocorrem processos museais, reconhecendo esses espaços como produtores de conhecimento em educação" e "promover o desenvolvimento e a difusão de pesquisas específicas por meio de agências de fomento científico, universidades e demais instituições da área", respectivamente (Ibid.).

Observa-se também que os três temas tratados nesse Eixo devem estar articulados, visto que não é profícuo que o pesquisador não tenha inserção na prática educativa e vice-versa. Buscando a integração das diferentes divisões constituintes da instituição museológica, o Item 9 recomenda "promover, em colaboração com outros setores dos museus, diagnósticos, estudos de público e avaliação, visando à verificação do cumprimento de sua função social e educacional" (Ibid.).

Na publicação Conceitos-Chave de Museologia, o termo museal é um neologismo recente e tem duas acepções: enquanto adjetivo serve para designar tudo o que se relaciona ao museu, distinguindo-se de outros domínios. Como substantivo designa o campo de referência no qual se desenvolvem não somente a criação, a realização e o funcionamento da instituição museu, mas também a reflexão sobre seus fundamentos e questões (DESVALLÉES; MAIRESSE, 2013, p. 54).

O Caderno da PNEM, na seção Glossário, destaca que

mais recentemente, o termo "Educação Museal" passa a ser utilizado como uma reivindicação tanto de uma modalidade educacional - que contempla um conjunto integrado de planejamento, sistematização, realização, registro e avaliação dos programas, projetos e ações educativas museais - quanto de um campo científico (IBRAM, 2018, p. 73) 
Esse termo quando acompanhado de um conjunto de significados "passa a carregar uma concepção de mundo, uma forma de entender a educação e o contexto em que ela se insere", ou seja, é compreendido como um conceito. Então, a educação museal é entendida "como parte de um processo de formação humana integral, [...] focado no indivíduo e sua interação com a sociedade, que valoriza suas formas de fazer e viver a cultura, a política, a história" (CASTRO, 2017).

Esse conceito imprime um novo significado para a educação em museus e tem seu foco na formação dos sujeitos em interação com o que é apresentado nestes espaços no sentido de engajá-los e comprometê-los com o processo histórico e cultural da sociedade.

Embora sejam muitos os desafios, para os museus, a implementação da PNEM é um instrumento para fortalecer o setor educativo, aglutinar os educadores e estimular o trabalho conjunto com as outras esferas da instituição para a concepção de exposições, atividades educativas e, principalmente, para o desenvolvimento de projetos de pesquisa. Desse modo, é possível construir uma educação museal de qualidade, valorizando-a e legitimando-a, tanto no que diz respeito às suas práticas quanto aos profissionais que as desenvolvem. Não é mais um esforço isolado de educadores ou de setores educativos e sim uma ferramenta que dá permanência, viabilidade e visibilidade interna e externa. Com esta Política, a educação museal ganha força e passa a ter um lugar efetivo no plano museológico ou plano diretor das instituições, acarretando outra forma de gestão nos museus.

\section{Pontos de reflexão}

Indiscutivelmente, a área de educação em museus, por meio de sua prática social e do desenvolvimento de pesquisas, vem formando um corpo de conhecimento cada vez mais consistente. A tentativa de definir de forma mais precisa seus termos e conceitos vem demarcando seu lugar dentro da instituição museológica, constituindo equipes profissionais que substituem o antigo voluntariado, muito comum na Europa e nos Estados Unidos. A produção na área tende a se tornar cada vez mais complexa, na medida do seu desenvolvimento. A elaboração deste artigo, que visitou muitos de seus estudos, provoca indagações para possíveis debates. Neste sentido, algumas questões foram suscitadas e estão aqui apontadas.

Ao mesmo tempo, reclama-se que não há diálogo entre as diferentes funções do museu, ou seja, conservação, pesquisa, educação e comunicação. O que se observa é que cada uma das 


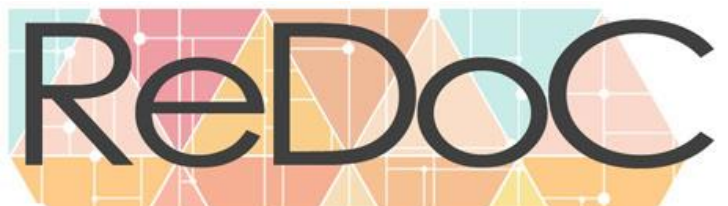

\section{Revista Docência e Cibercultura}

funções é vista de forma isolada. Quando se passa a usar o termo "museal" para qualificar as ações e o arcabouço da educação que ocorre nos museus, cabe uma questão: como introduzir a educação museal de forma mais integrada com a museologia, visto que é perceptível uma resistência entre estas áreas?

No transcorrer do presente texto, as resistências entre a educação em museus e a museologia são mencionadas em vários momentos. Esta oposição tem sido observada no âmbito da instituição. No entanto, essa rejeição tem origem na quase inexistência da disciplina que trata da educação em museus nos cursos de formação de profissionais da museologia. Nas diretrizes da PNEM, o Item 5 do Eixo II - Profissionais, Formação e Pesquisa - destaca um aspecto importante associado aos cursos de formação: "potencializar o conhecimento específico da educação museal de forma a consolidar esse campo, por meio [...] do estímulo à viabilização de cursos de nível superior em educação museal" (IBRAM, 2017, p. 6). Aqui cabe ainda outra indagação: a concretização de um curso específico para formar o educador museal irá garantir o diálogo com os profissionais formados em museologia?

Além dos questionamentos sublinhados acima, há outro que está relacionado à consolidação do campo da educação museal. Levando em conta as definições de Bourdieu (1997) sobre o conceito de campo, é possível considerar a educação museal como um campo de conhecimento autônomo e com elevado capital científico?

Diante de um quadro, no qual a disciplina que trata dos conteúdos da educação em museus ocupa lugar de pouca importância nos cursos de formação de profissionais da museologia e tem ainda pouca inserção nos cursos e grupos de pesquisa em programas de pós-graduação, onde a produção de conhecimento se faz, é mais acertado entender a educação museal como um campo de conhecimento, ainda em construção, com pouca autonomia e em processo de acúmulo de capital científico. Assim, o empenho para o adensamento deste tipo de educação, valorizando-a e legitimando-a, tanto no que diz respeito às suas práticas quanto aos profissionais que as desenvolvem deve ser constante.

\section{REFERÊNCIAS}

ALLARD, Michael; LANDRY, Anik; MEUNIER, Claire. Où va l'éducation muséale? In: ÉMOND, A. M. (Ed.). Education in museums as seen in Canada, the United States and Europe: research on programs and exhibitions. Canadá: Éditions MultiMondes, 2006. p. 9-20. 


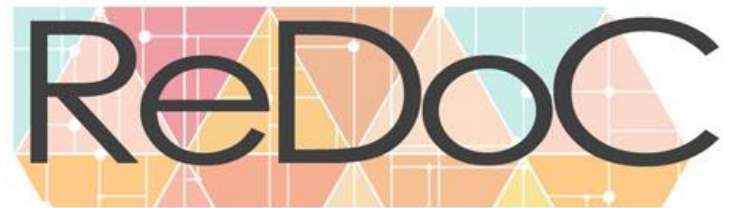

\section{Revista Docência e Cibercultura}

ALLARD, Michael; LEFEBVRE, Bernard. (Ed.). La formation en muséologie et en éducation muséale à travers le monde. Canadá: Éditions MultiMondes, 2001.

AVILÉS, Rosa María Hervás; LÁZARO, Antonia María Sánchez; IBÁÑEZ, Magdalena Castejón. El museo como espacio de desarrollo local. Una experiencia de participación ciudadana. In: DUFRESNE-TASSÉ, C.; LARAIGNÉE, A. M. (Ed.). Special issue on research. ICOM Education 27. Roma: Edizioni Nuova Cultura, 2017. p. 45-70.

BALLÉ, Catherine; POULOT, Dominique. Mussées na Europe: une mutation inachevée. Paris: La Documentation Française, 2004.

BOURDIEU, P. Razões práticas: sobre a teoria da ação. Campinas: Papirus, 1997.

CASSIN, Michael. The "American" (U.S.) Experience - a swinging pendunlum? In: ÉMOND, A. M. (Ed.). Education in museums as seen in Canada, the United States and Europe: research on programs and exhibitions. Canadá: Éditions MultiMondes, 2006. p. $21-24$

CASTRO, F. O que é educação museal? Educação Museal. 2017. Disponível em: $<$ http://educacaomuseal.org/iniacutecio/o-que-e-educacao-museal >.

Acesso em: 8 mar. 2019.

CAZELLI, Sibele; COIMBRA, Carlos Aberto Quadros; VALENTE, Maria Esther. Educação no MAST: 30 anos de ações e pesquisas. In: VALENTE, M. E.; CAZELLI, S. (Org.). Educação e divulgação da ciência. Rio de Janeiro: Museu de Astronomia e Ciências Afins, 2015. p. 144-179. (Coleção MAST - 30 anos de Pesquisa, v. 2). Disponível em: <http://site.mast.br/hotsite_mast_30_anos/pdf_02/volume_02.pdf>. Acesso em: 26 fev. 2019.

CHAGAS, I. Aprendizagem não-formal/formal das ciências. Relação entre os museus de ciência e as escolas. Revista de Educação. Departamento de Educação da Faculdade de Ciências da Universidade de Lisboa, v. 3, n. 1, p. 51-59, 1993.

COIMBRA, Carlos Alberto Quadros; CAZELLI, Sibele; CORRÊA, Maíra Freire Naves; GOMES, Isabel Lourenço. Ampliando audiências: por um museu menos excludente. Diálogos de la Comunicación, n. 88, p. 1-21, 2014. Disponível em: $<$ http://www.dialogosfelafacs.net/wpcontent/uploads/2014/01/88_Revista_Dialogos_Ampliando_audiEncias_por_um_museu_men os_excludente.pdf >. Acesso em: 7 fev. 2019.

COOMBS, P. H. A crise mundial da educação. São Paulo: Editora Perspectiva, 1968. 


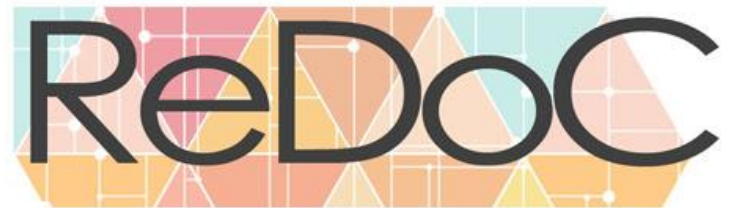

\section{Revista Docência e Cibercultura}

CORDIER, Jean-Pierre. Les formations muséales en france. In: ALLARD, M.; LEFEBVRE, B. (Ed.). La formation en muséologie et en éducation muséale à travers le monde. Canadá: Éditions MultiMondes, 2001. p. 15-38.

COSTA, Andréa Fernandes. Museu de Ciência: instrumentos científicos do passado para a educação em ciências hoje. (Dissertação), Programa de Pós-Graduação em Educação PPGEdu. (Mestrado em Educação), Universidade Federal do Estado do Rio de Janeiro UNIRIO, Rio de Janeiro, 2009.

CRANE, V.; NICHOLSON, T.; CHEN, M. Informal science learning. In: What the research says about television, science museums and community-based projects? Epharata, Pennsylvania: Science Press, 1994.

DESVALLÉES, André; MAIRESSE, François. (Org.). Dictionaire Encyclopédique de Muséologie. Paris: Armand Colin Éditeur, 2011.

DESVALlÉES, André; MAIRESSE, François. (Ed.). Conceitos-chave de Museologia. SOARES, B. B.; CURY, M. X. Tradução e Comentários. São Paulo: Comitê Brasileiro do ICOM, Conselho Internacional de Museus, Pinacoteca do Estado de São Paulo, Secretaria do Estado de São Paulo, 2013.

DIERKING, L. D.; FALK, J. H. Science education: informal editorial policy statement. Science Education, v. 83. n. 2, p. 113-114, 1999.

DIERKING, L. D.; MARTIN, L. M. W. Guest editorial: introduction. Science Education, v. 81, n. 6, p. 629-631, 1997.

FALK, J. H.; KORAN, Jr. J. J.; DIERKING, L. D. The things of science: assessing the learning potential of science museums. Science Education, v. 70, p. 503-508, 1986.

FÁVERO, Osmar. Tipologia da educação extra-escolar. Rio de Janeiro: Fundação Getúlio Vargas, Instituto de Estudos Avançados em Educação, 1980.

GESCHÉ-KONING, Nicole. The "American" (U.S.) Experience - a swinging pendunlum? In: ÉMOND, A. M. (Ed.). Education in museums as seen in Canada, the United States and Europe: research on programs and exhibitions. Canadá: Éditions MultiMondes, 2006. p. 25-50.

GODIN, B.; GINGRAS, Y. What is scientific and technological culture and how is it measured? Public Understanding of Science, v. 9, n. 1, p. 43-58, 2000.

GOHN, M. G. Educação não-formal e cultura política: impactos sobre o associativismo do terceiro setor. São Paulo: Cortez, 1999. (Coleção questões da nossa época; v. 71). 
GRUPO DE ESTUDO E PESQUISA EM EDUCAÇÃO NÃO FORMAL E DIVULGAÇÃO EM CIÊNCIA (GEENF). Apresentação. Disponível em: <http://www.geenf.fe.usp.br/v2/?page id=673>. Acesso em: 8 mar. 2019.

HOFSTEIN, A.; ROSENFELD, S. Bridging the gap between the formal and informal science learning. Studies in Science Education, v. 28, p. 87-112, 1996.

IBRAM - INSTITUTO BRASILEIRO DE MUSEUS. Documento Preliminar da PNEM. Brasília: Ibram, 2017. Disponível em: <http://pnem.museus.gov.br/wpcontent/uploads/2012/08/DOCUMENTO-PRELIMINAR1.pdf>. Acesso em: 4 mar. 2019.

IBRAM - INSTITUTO BRASILEIRO DE MUSEUS. Caderno da Política Nacional de Educação Museal. Brasília, DF: IBRAM, 2018. Disponível em: <https://www.museus.gov.br/wp-content/uploads/2018/06/Caderno-da-PNEM.pdf >.

Acesso em: 4 mar. 2019.

LOPES, M. M. A favor da desescolarização dos museus. Educação e Sociedade, v. s/n, n. 40, p. 443-455, 1991.

LOPES, M. M. Convite à leitura. In: MIRANDA, G. G.; SANTOS, M. J. V. C; ESTEVÃO, S. N. M.; FONSECA, V. M. M. (Org.). A função educativa dos museus. Niterói - RJ: Muiraquitã, 2008. p. 19-23.

MCMANUS, Paulette. Topics in museums and science education. Studies in Science Education, v. 20, p. 157-182, 1992.

MCMANUS, Paulette. Uma palavra em seu ouvido... o que você quer dizer quando fala, ou pensa a respeito de educação (formal e informal), aprendizagem e interação? In: MARANDINO, M.; ALMEIDA, A. M.; VALENTE, M. E. A. (Org.). Museu: lugar do público. Rio de Janeiro: Editora Fiocruz, 2009. p. 47-61.

RANGEL, Aparecida; HARDUIM, Barbara; SEIBEL, Maria Ilone. A rede de educadores em museus do estado do Rio de Janeiro: uma contribuição ao campo da educação não-formal. In: CAZELLI, S.; FALCÃO, D.; VALENTE, M. E. (Org.). Encontro Internacional de Educação Não Formal e Formação de Professores, 2012, Rio de Janeiro, RJ. Rio de Janeiro: MAST, 2012. 1 CD-ROM. Disponível em:

<http://site.mast.br/multimidias/encontro_internacional_de_educacao_nao_formal_e_formaca o_de_professores/pdfs-comunic/ResumoEstendido_Aparecida_Rangel.pdf $>$. Acesso em: 28 fev. 2019. 


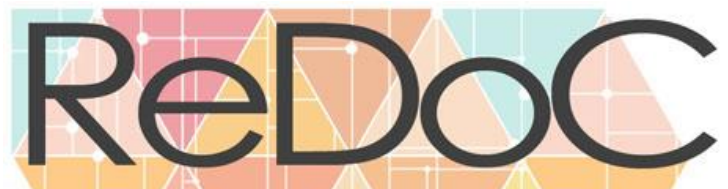

\section{Revista Docência e Cibercultura}

ROGERS, A. Looking again at non-formal and informal education: towards a new paradigm, 2004. Disponível em: <www.infed.org/biblio/non_formal_paradigm.htm>. Acesso em: 7 fev. 2019.

TERUGGI, Mario. Museums and scientific and technological development. Museum, v. 25, n. 3, p. 127-131, 1973.

TRILLA, J. La educación fuera de la escuela. Barcelona: Ariel, 1998.

VALENTE, Maria Esther. Momentos dos museus de ciência e tecnologia no Brasil. In: MARANDINO, M.; ALMEIDA, A. M.; VALENTE, M. E. A. (Org.). Museu: lugar do público. Rio de Janeiro: Editora Fiocruz, 2009. p. 211-227.

VALENTE, Maria Esther. Da dimensão à função educativa no museu: algumas incursões. In: COSTA, A. F.; RANGEL, A. M. S.; CASTRO, F. S. R.; HENZE, I. A. M.; VALENTE, M. E.; SOARES, O. J. (Org.). O lugar da educação nos museus. Rio de Janeiro: Museus Castro Maia, 2018. p. 41-48. (Museu de Ideias - Edição 2017). Disponível em:

$<$ http://rubi.casaruibarbosa.gov.br/handle/20.500.11997/8886? mode=full $>$. Acesso em: 4 mar. 2019.

WELLINGTON, J. Formal and informal learning in science. The role of the interactive science centers. Journal of Research in Science Teaching, v. 17, n. 2, p. 99-104, 1990. 